\title{
PIERRE GRINGORE, CEuvres moralisatrices I (1499-1510)
}

\section{Michele Mastroianni}

\section{OpenEdition \\ Journals}

\section{Edizione digitale}

URL: https://journals.openedition.org/studifrancesi/44878

DOI: $10.4000 /$ studifrancesi.44878

ISSN: 2421-5856

\section{Editore}

Rosenberg \& Sellier

\section{Edizione cartacea}

Data di pubblicazione: 1 août 2021

Paginazione: 360

ISSN: 0039-2944

\section{Notizia bibliografica digitale}

Michele Mastroianni, «pierRe Gringore, Euuvres moralisatrices I (1499-1510)», Studi Francesi [Online], 194 (LXV | II) | 2021, online dal 01 septembre 2021, consultato il 15 octobre 2022. URL: http://

journals.openedition.org/studifrancesi/44878; DOI: https://doi.org/10.4000/studifrancesi.44878

Questo documento è stato generato automaticamente il 15 octobre 2022.

\section{(c)}

Creative Commons - Attribuzione - Non commerciale - Non opere derivate 4.0 Internazionale - CC BYNC-ND 4.0

https://creativecommons.org/licenses/by-nc-nd/4.0/ 


\title{
PIERRE GRINGORE, CEuvres moralisatrices I (1499-1510)
}

\author{
Michele Mastroianni
}

\section{NOTIZIA}

PIERRE GRINGORE, CEuvres moralisatrices I (1499-1510), éd. critique par C.J. Brown, Genève, Droz, 2020, 842 pp.

1 Bella edizione critica questa di Cynthia J. Brown, che offre agli studiosi un terzo volume delle Euvres di Gringore all'interno del quale sono curati con dovizia filologica i testi delle prime opere moralizzanti del noto autore cinquecentesco, in questo caso attivo fra il 1499 e il 1510. Trattasi in particolare di tre scritti in versi: Le Chasteau de labour (1499), Le Chasteau d'amours (1500), Les Folles Entreprises (1505), scritti accompagnati da due brevi poemi. Il primo, del 1505, ha come titolazione La Complainte de Trop Tard Marié (1505), il secondo La Coqueluche (1510). Si tratta di opere elaborate in un periodo di attività poetica di Pierre Gringore che coincide con una situazione politica e sociale particolarmente delicata in Francia, sotto la reggenza di Louis XII e, come noto, in Europa. Un periodo che Gringore tenta di ricostruire attraverso una disamina anche ermeneutica che tocca aspetti tanto relativi al vizio quanto alle virtù dei Francesi, secondo una prospettiva esegetico-edificante che, anche in una veste di leggerezza e divertimento, si serve di ambientazioni e contestualizzazioni allegoriche spesso riprodotte attraverso incisioni su legno, talvolta riprodotte nelle edizioni qui presentate e curate dall'editore moderno. Nello specifico ne Le Chasteau de Labour e ne Les Folles Entreprises. Attraverso una narrazione suggestiva e, in particolare, «à travers de personnifications et la voix du narrateur, désigné comme L'acteur, Gringore finit par attaquer des institutions judiciaires et religieuses ainsi que des faiblesses humaines, parfois de la perspective d'un juge sévère, comme dans ses longs poèmes, parfois d'un point de vue plus compatissant et même amusant, comme dans La Complainte de Trop 
Tard Marié et La Coqueluche. Ainsi se dévoile la diversité des capacités littéraire, poétique et rhétorique de l'auteur».

2 Questo volume, quindi, che si presenta come studio solido e utile, non solo offre per la prima volta allo specialista l'edizione critica de Le Chasteau d'amours e de La Complainte de Trop Tard Marié, ma anche le edizioni de Le Chasteau de labour, de La Coqueluche e de Les Folles Entreprises che propongono per la prima volta testi in edizioni critiche moderne che presentano oltre ad annotazioni filologiche ricche e precise per dati e varianti riportati in nota, rimandi puntuali a tutte le versioni esistenti. Ciascuno dei testi qui editati è preceduto da introduzioni che ricostruiscono con precisione il contesto storico-letterario, fornendo al lettore un riassunto molto utile delle opere. Chiude il volume un apparato critico (pp. 692-725), nonché un folto glossario. Non possiamo quindi che accogliere con plauso questo bel lavoro che apporta alla critica di settore un contributo scientificamente solido e originale. 